\title{
The Pandemic Dilemma: When Philosophy Conflicts with Public Health
}

\author{
Dien Ho
}

Center for Health Humanities, Massachusetts College of Pharmacy and Health Sciences, Boston, Massachusetts 02115, USA Corresponding author: Email. Dien.ho@mcphs.edu

One of the most heartbreaking aspects of the COVID-19 pandemic is how we ignored the warnings epidemiologists and infectious disease experts had been sounding for decades. The question had always been a matter of when and not if a global infectious crisis would occur. Yet, when COVID-19 began to spread around the world, country after county was caught flatfooted, woefully unprepared both materially and strategically. The cause of our collective failure stems less from skepticism toward what scientists and epidemiologists have been telling us; instead, a number of social and political institutions provide strong disincentives to proper preparation, as I will argue. Three examples stand out: representational democracy, a state's obligation to its citizens, and unfettered dissemination and consumption of information. These institutions and practices are deeply entrenched and highly valued in the United States. If they are indeed barriers to effective responses to a pandemic, then we must consider if and to what extent we are willing to sacrifice them in combating the next global threat.

Consider the political leadership and foresight needed to prepare for a pandemic. The early days of COVID-19 painfully revealed our lack of critical resources such as personal protective equipment (PPE) ventilators, logistical networks to mobilize personnel, and clinical space. It took the Center for Disease Control over a year from the start of the outbreak to acknowledge that COVID-19 spreads largely through airborne particles; the usefulness of masks in mitigating the contagion might have been uncertain in the early months. But the possibility, if not likelihood, of an airborne pathogen was surely well-known to public health officials, especially given the warnings coming from Asia. The lack of PPE was not the result of SARS-CoV-2 catching us off guard with a novel vector of infection; rather, it was our political failure to prepare for a likely scenario. This failure can be partly attributed to political systems that reward short-term achievements over long-term catastrophic preparations. In the United States, federal election cycles range from 2 years (House of Representatives) to 4 years (President) to 6 years (Senate). Elected officials need to deliver tangible political results if they are to make a convincing case for their reelection. Spending tax dollars stockpiling PPE that might or might not prove visionary is a risky reelection strategy. If a pandemic hits, voters see the preparation as par for the course. If a pandemic does not hit, a politician has little to show except a warehouse filled with soon-to-expire supplies. Preparing for a pandemic constitutes a kind of "invisible project" that, if done right, is invisible to the average voter. It is akin to infrastructure maintenance. So long as water comes out of the tap, the badly corroded water main remains hidden and out of the mind of voters. A shiny new school makes for a great photo-op; a newly installed sewer line hardly garners the same enthusiasm. Without the buy-in from voters to spend their tax dollars on public health preparation, a political leader has little to no incentive to do what is necessary. Representational democracy with relatively short election cycles might be particularly vulnerable to unpreparedness.

As COVID-19 vaccines became available, it was apparent that as much as many wealthy countries were committed to ensuring that poorer ones had access to the vaccines, several states including the United States, Russia, and China initially opted out of collaborative efforts such as World Health Organization-sponsored COVAX. Even among those who participate in it, there have been reports of "side deals" between wealthier countries and pharmaceutical companies to guarantee these countries' 
exclusive access to the vaccines. As much as vaccine nationalism stinks of anti-altruistic instincts of realpolitik, the very concept of a political state might give strong ethical reasons why countries ought to look out for "their own" first. Classic Enlightenment philosophies tell us that individuals form society in order to escape from the brutish short life of the state of nature. Indeed, pooling resources together, cooperating in accordance with some (implicit) social contract, and outsourcing certain tasks such as national defense to the state are wise moves on the part of individuals. Citizens are entitled to their social services precisely because they have formed an implicit pact of mutual support: I contribute to these services (even if I do not use them) so that we all have access to them.

This agreement and the tax dollars that we may pay distinguish (roughly) the entitlements of citizens from noncitizens. Both Moderna's and Pfizer's vaccines were developed with significant financial contribution from the United States government. A citizen's access to the vaccine is grounded in our contract of mutual aid. To be sure, we often provide assistance to those in need regardless of their citizenship status. From emergency care to foreign aid, moral decency demands that we help those who happen to fall outside of our realm of social contract. When political leaders choose to prioritize their own citizens' vaccination over the needs of other countries, they are providing what a state owes to its citizens. After all, if everyone in the world has equal claim to a state's resources, why would anyone bother to join a society? The very concept of states as autonomous bodies with citizens bound by the commitment of mutual aid means that there are different entitlements and treatments between those who are citizens and those who are not. This special political obligation makes any coordinated global response in which individuals are treated equally regardless of nationality particularly challenging. The lack of any global coordinating body is merely a technical problem. The deeper issue is how to justify taking from citizens what they are politically entitled to and giving it to noncitizens.

Coordinated state actions such as contact tracing, mandated testing, and social distancing are only as effective as the rate of compliance. One obvious way to increase compliance is to penalize individuals who violate the rules. More than the logistical challenges that are involved in maintaining a high level of state surveillance, there is the problem of civil liberty. A less draconian top-heavy means is to cultivate a ground-up sense of communal solidarity. In other words, one might encourage compliance by highlighting the value of promoting collective interests. Anti-littering campaigns, voting drives, and recycling initiatives are all examples that show it is possible to grow a ground-up culture of solidarity. Indeed, one might argue that countries that have had prior experiences with infectious outbreaks handled COVID-19 more effectively since their citizens were well-versed in the value of compliance. For the United States, however, a grassroot swell of solidarity requires the dissemination and consumption of accurate information, trust in governmental agencies, and broad empathy for one's fellow Americans. All three of these were in short supply at the start of the pandemic and the difficulties were compounded by the weaponizing of public health responses for political gains. More conceptually, unless information dissemination is controlled such that misinformation would not take root, individuals can always be exposed to inaccurate information peddled by those who have much to gain. Here, the information freedom that we so cherish might run contrary to the implementation of public health responses that require a high degree of buy-ins.

The three obstacles that I outlined above are obviously not insurmountable. The point is to realize that effective strategies against a pandemic can carry a significant moral and political price. In one sense, the solution to stopping the COVID-19 infection is straightforward. With an incubation period of approximately 14 days, SARS-CoV-2 would have nowhere to go if we suspend any person-to-person contact for 2 weeks. The price of such a dramatic response would be intolerably high. From folks dying without access to healthcare to a collapse of our economy and other social institutions, we might be able to rid ourselves of the virus but only at a terribly high price. An infectious disease attacks the reality that human beings are social animals who have created a social world. Our interdependence is what accounts for our tremendous power but when the world is metaphorically flat (to borrow a phrase from Thomas Friedman), there is nowhere to hide.

However deadly and disruptive COVID-19 has been, it pales in comparison to the 1918 influenza pandemic. Infectious disease epidemiology along with public health have improved significantly in the 
last 100 years. Nonetheless, the odds are good that COVID-19 is but a dress rehearsal: a more deadly global crisis lurks on the horizon. In formulating how we prepare and confront the next challenge, it is imperative that we keep in mind the social, moral, and political costs that we are willing to bear. Ultimately, deciding which value is too costly to sacrifice must be a collective matter reflecting the wishes of stakeholders. Fighting a global threat without democratic input will almost guarantee a lack of compliance. Worse still, imposing a particular tradeoff between public health and what we value without broad consensus smacks of paternalistic imposition. After all, we do not want to defend against a pandemic only to be left with nothing to defend. 


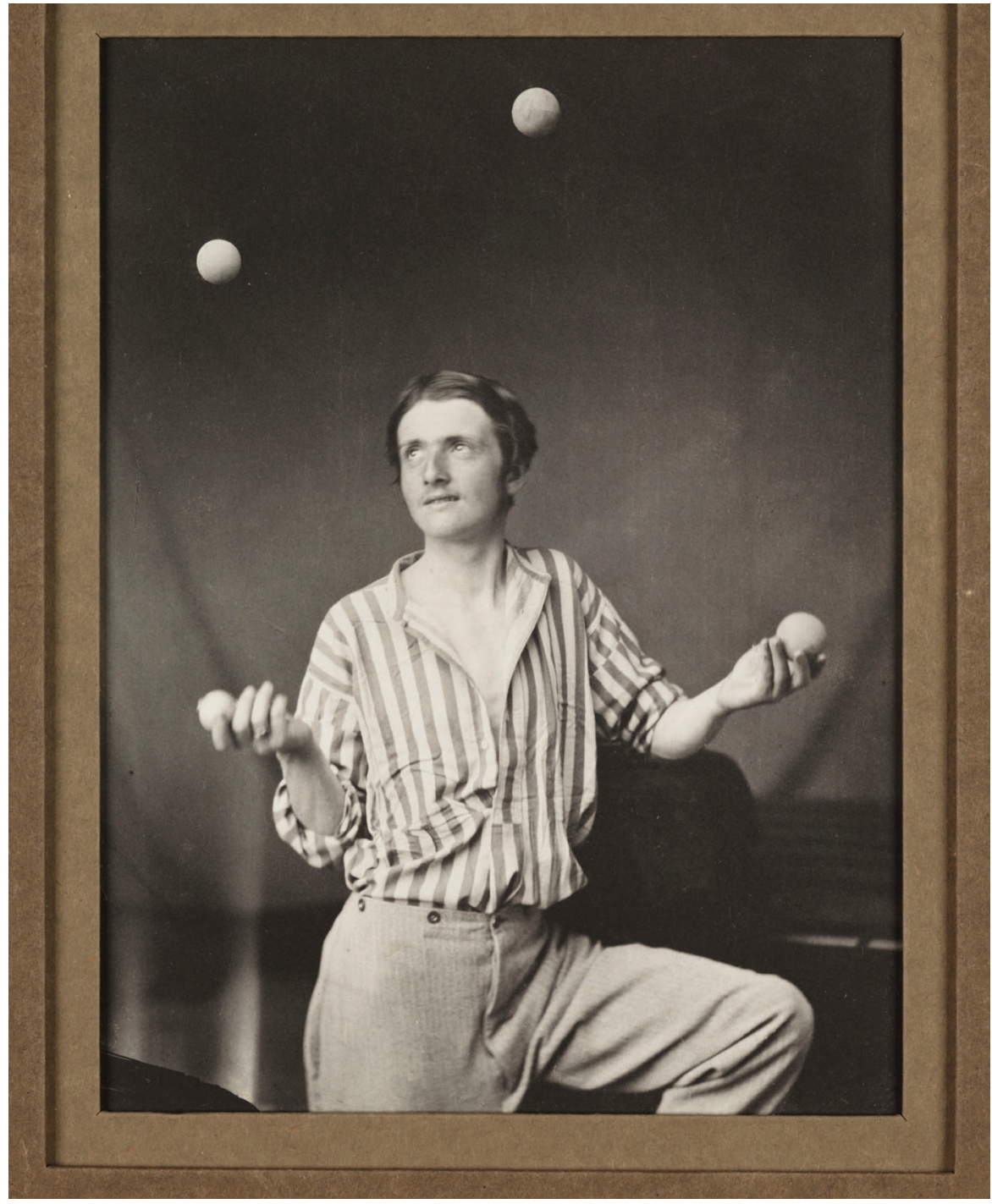

Rejlander, Oscar Gustave (1813-1875) 'The Juggler', mid-19th century.

Location: The V\&A's Royal Photographic Society Collection, Victoria and Albert Museum, London, Great Britain Photo Credit: @ Royal Photographic Society Collection / Victoria \& Albert Museum, London/Art Resource, NY, Reproduced by permission 